\title{
Keywords
}

maternal education; depression; children's achievement

\begin{abstract}
American women are increasingly pursuing higher education to the point that the historical gender gap in collegiate and post-collegiate graduation has not only closed, but reversed (Buchman and DiPrete 2006). Given that women still have primary responsibility for raising children (Sayer 2005), these trends in female educational attainment have implications for children's well-being in both the short and long term. The impact of maternal education on child health, psychosocial, and cognitive outcomes has been established with experimental and quasi-experimental designs, and the effects of early child development and learning on status attainment during adulthood are well-documented (Currie and Moretti 2003; Gennetian, Magnuson, and Morris 2008; Palloni 2008). In this way, the education of mothers conveys accumulating advantages for children throughout their life course that underlie the intergenerational transmission of socioeconomic inequality.

Importantly, this intergenerational transmission is not driven solely by the human and financial capital returns to education. It is also channeled through the psychological resources that educational attainment can bring (Davis-Kean 2005; Mirowsky and Ross
\end{abstract}

Reprints: http://www.sagepub.com/journalsReprints.navPermissions: http://www.sagepub.com/journalsPermissions.nav Corresponding Author: Jennifer March Augustine, Department of Sociology and Population Research Center, University of Texas at Austin, 1 University Station A1700, Austin, TX 78712-1088, jmarch@ mail.utexas.edu. 
2003). Among these psychological resources, mental health—typically conceptualized as the absence of depression - has clear consequences for children's psychosocial development and the reproduction of stratification across generations (Cavanagh and Huston 2006; Meadows, McLanahan, and Brooks-Gunn 2007). Specifically, maternal depression often triggers harsh or inconsistent parenting behaviors that precipitate behavioral problems in young children, such as anxiety or "acting out" (McLoyd 1998). The consequences of these depression effects on parenting could extend to the academic domain. For example, depression can lead mothers to become disengaged and less apt to construct stimulating activities for their children, such as reading or playing learning games (McLoyd 1998). Yet the role of maternal depression in shaping this connection between mothers' educational attainment and children's achievement has not been adequately delineated. This study aims to clarify the relationship between these two concepts.

Drawing on the life course perspective, we view maternal depression and child learning as a set of interlocking trajectories, or elements of "linked lives," that are both affected and moderated by women's educational attainment. We anticipate that women with consistently low levels of depression will have children who post higher rates of learning during elementary school than children of mothers who demonstrate high and/or increasing depressive symptoms, and that maternal educational attainment will factor into this linkage by predicting depression trajectories. At the same time, because education engenders a wide range of capacities, skills, and resources that mothers draw on to support children's learning (Davis-Kean 2005) — and potentially buffer the effects of depression on learning—we also expect maternal education to factor into this linkage by moderating the extent to which mothers' depression affects their children's learning. Combining these ideas, we hypothesize that children of more educated mothers will have a double academic advantage: Their mothers will be less likely to exhibit depressive symptomology, and they themselves will be less affected by whatever symptoms their mothers do exhibit.

This dynamic intergenerational model will be tested by applying latent growth curve modeling techniques to data from the multi-site birth cohort study of children and their parents participating in the National Institute of Child Health and Human Development (NICHD) Study of Early Child Care and Youth Development (SECCYD). By focusing on the consequential early stages of learning, the results of such research will contribute to the growing literatures in medical sociology and the sociology of education that consider how the health returns to educational attainment filter into the status attainment of the next generation (Entwisle, Alexander, and Olson 1997; Lynch 2003).

\section{Theory and Evidence}

\section{Maternal Depression and Children's Early Learning}

Mothers who pursue more education have children with better current and future life course prospects. This link extends across national borders (Mare and Maralani 2006) and has a causal component that is independent of the numerous factors that select women into higher levels of educational attainment (Currie and Moretti 2003; Gennetian et al. 2008; Oreopoulos, Page, and Stevens 2006). Moreover, this link is not solely explained by the obvious income, employment, or marital/fertility correlates of increased education. Rather, it 
is also related to the constellation of capacities, skills, and resources developed through educational experiences that help mothers promote their children's learning and successful passage through the educational system (Davis-Kean 2005; Kingston et al. 2004; Mirowsky and Ross 2003).

This study is predicated on a proposition that maternal depression (or absence thereof) is a component of the pool of such non-economic, non-cognitive factors that underlie the intergenerational transmission of inequality through education. The positive association between women's education and their children's achievement is well documented, as is the negative association between women's education and their depression (Magnuson 2007; Mirowsky and Ross 2003). However, the direct association between maternal depression and child learning has not often been examined. Nonetheless, there is ample theory and empirical evidence suggesting a connection. Based on this evidence, our conceptual model is that depression affects parenting behaviors linked to child learning, which in turn affects child achievement.

This conceptual model is motivated by the idea that the particular parenting behaviors that promote children's learning require active engagement. Such behaviors include reading to children, taking children on intellectual trips (e.g., museum, library), and helping with homework, as well as day-to-day conversation that fosters children's language development and cognitive skills (Amato and Fowler 2002; Bornstein and Bradley 2003; Magnuson 2007). Depression, however, can lead mothers to be more disengaged, reduce social interaction with their children, be less responsive (and encouraging), and have difficulty engaging consistently in instrumental practices that support learning and schooling at home (Downey and Coyne 1990; Mistry et al. 2004). Thus, following the life course principle of linked lives - the idea that trajectories of family members are linked to each other over time (Elder 1998) — the first step in this study is to examine the extent to which mothers' depression has implications for children's learning as they enter into and progress through formal schooling.

\section{Bringing in Maternal Education}

We anticipate that the lower average depression of more educated women will be one reason that their children post higher rates of learning across elementary school (Meadows et al. 2007; McLoyd 1998; Mirowsky and Ross 2003). Yet this mediational pathway may not be the only way that depression factors into the intergenerational linkage between mothers' and children's educational experiences. The effect of maternal depression on children's learning may also vary as a function of maternal education. Given the personal resources that education cultivates, and that ultimately help establish women's place in the larger stratification system, maternal education may not simply predict women's depression trajectories. It may also condition the link between depression and children's achievement by buffering (or minimizing) the risks that maternal depression pose to children's learning (Currie and Moretti 2003).

Among these resources, education increases women's knowledge about how the educational system works and promotes norms about academic success and parental investment (Alexander, Entwisle, and Bedinger 1994; Davis-Kean 2004; Sayer, Gauthier, and 
Furstenberg 2004). In this way, depression may affect some aspects of parenting among more educated mothers but have fewer consequences for how they manage their children's learning. For example, better-educated women are more likely to arrange academically enriching care for their children before they enroll in school, and they're also more likely to register their children for organized activities after school and during the summer once children have entered school (Alexander, Entwisle, and Olson 2007; Augustine, Cavanagh, and Crosnoe 2009; Chin and Phillips 2004). These pro-academic experiences directly provide children with learning opportunities that may not be available in the home when mothers are experiencing depressive symptoms, and they may also indirectly cultivate children's enjoyment of learning and academic aspirations (Alexander et al. 1994; DavisKean 2005; Lareau 2004).

These patterns may also extend to maternal school involvement, which is consistently linked to children's learning and achievement, especially in the early years of formal schooling (Hoover-Dempsey and Sadler 1997). Indeed, there is some indication that even among mothers suffering mental distress, educational attainment continues to exert a direct effect on their school involvement (Oyserman et al. 2002). Better-educated women are more likely to participate in school activities and communicate with teachers and parents, and involvement may also extend to children's preschool activities (e.g., selection of child care, lessons). This continued involvement is likely a result of the social networks (e.g., relationships with teachers, parents) and organizational skills (e.g., to secure time for school involvement) that accrue through educational attainment (Carbonaro 1998; Coleman 1988; Mirowsky and Ross 2003). Organizational skills may also help mothers structure their children's time at home doing learning activities, such as studying or playing learning games, that do not necessarily require parental participation (Bianchi and Robinson 1997). Given the resources and practices associated with maternal education, therefore, a second step in the analysis is to examine whether maternal depression will be less consequential for the learning of children whose mothers have higher levels of education.

\section{Taking a Dynamic Approach}

As a final consideration, researchers regularly recognize that academic achievement is a dynamic process, but they often rely on point estimates to capture maternal depression, even though it generally varies over time. Even in cases reaching clinical levels, depression ebbs and flows alongside other stressful life events related to income, work, relationships, and family (Downey and Coyne 1990; George and Lynch 2003; Katz and Beach 1997; Mistry et al. 2004). These fluctuations can affect the course of children's development. Consequently, knowledge of the link between maternal depression and child learning can be better understood by looking into how both unfold over time in relation with each other. Such a dynamic approach can assess the degree to which the level and stability of maternal depression matters to children while also identifying critical points in children's lives in which they are more or less vulnerable to having depressed mothers (Crosnoe and Huston 2007; Downey and Coyne 1990).

Following prior research on the transition to elementary school (Pianta, Cox, and Snow 2007), children's learning may be most sensitive to mothers' depression—or changes in 
depression-during this critical period when their educational careers begin and academic trajectories take root. Indeed, the transition into elementary school is thought to mark a first step in the intergenerational transmission of inequality because initially small socioeconomic differences in achievement quickly contribute to larger differences that set children on divergent academic trajectories (Alexander and Entwisle 1988; Alexander et al. 2007). Thus, although children's academic trajectories unfold across elementary school, they may actually be fastened during critical periods of influence, namely, right before school entry (NICHD Early Child Care Research Network 2005).

To these ends, the first objective of this study is to simultaneously model two trajectories: (1) maternal depression, beginning when children are 54 months old, immediately before the transition to elementary school, through the fifth grade, and (2) children's trajectories of basic skill development from the start to the end of elementary school (first to fifth grade). The second objective will then be to examine the degree to which these two trajectories are interrelated over time. Specifically, we will examine the degree to which maternal depression trajectories mediate maternal educational differences in children's learning trajectories and whether the link between maternal depression and child learning varies as a function of maternal education. Last, we will explore possible critical timing points in this linkage.

\section{Method}

\section{Data}

The NICHD Study of Early Child Care and Youth Development (SECCYD) is a longitudinal study following children from birth through high school (NICHD Early Child Care Research Network 2005). Data collection began in 1991, when families were recruited from hospitals located in or near ten U.S. cities: Little Rock, Arkansas; Irvine, California; Lawrence, Kansas; Boston, Massachusetts; Philadelphia, Pennsylvania; Pittsburgh, Pennsylvania; Charlottesville, Virginia; Morganton, North Carolina; Seattle, Washington; and Madison, Wisconsin. During selected 24-hour sampling periods, 8,986 women were visited in the hospital shortly after giving birth to determine eligibility for the study and their willingness to participate. There were three eligibility criteria: (1) the mother had to be at least 18 years of age and conversant in English, (2) the infant had to be a singleton and healthy, and (3) the family could not be planning to move within the following year. A total of 1,364 families were enrolled in the study. Although not nationally representative, this sample was economically and geographically diverse.

The SECCYD was originally designed to answer questions about the link between children's experiences in child care and their developmental outcomes. It has since followed these children at regular intervals into elementary school and through the start of high school. Because the study measured children's academic skills and mother's depressive symptoms both before and after children's transition to elementary school, and because it collected information on important covariates (e.g., income, family structure, mothers' employment status), it offers a valuable opportunity to investigate the research questions of the present study. 
The analytical sample for this study began with the 1,030 children who participated in the first grade follow-up. From this sample, 8 children were excluded because they lacked valid data on both maternal depression and achievement at all data collection points, and another 20 were excluded because they lived with an alternative primary caregiver during elementary school. These steps resulted in a final analytical sample of 1,012 children. As explained shortly, missing data estimation techniques allowed us to retain all cases in this sample in all analyses.

\section{Measures}

Academic achievement-In first, third, and fifth grades, children took two subtests of the Woodcock-Johnson Psycho-Educational Battery-Revised (WJ-R), a widely used comprehensive battery for assessing academic skill levels (Woodcock, McGrew, and Mather 2001). The "applied problems" set is a test of simple math problems and calculations. The "letter-word identification" set is a test of reading identification. The two subtests are comprised of individual items arranged in order of difficulty, with the easiest item presented first and the most difficult items presented last. Individual items were administered only until the study child's operating range was established (i.e., the child no longer answered a certain number of consecutive questions correctly). Raw scores were created by summing the number of correct responses plus a score of 1 for every item in the test below the child's minimum operating level (i.e., those questions not administered in which the child has essentially a $100 \%$ chance of responding correctly). Because of this unique design, raw scores must be converted to $\mathrm{W}$ scores for longitudinal analyses. The $\mathrm{W}$ score is a special transformation of the Rasch ability scale that contains mathematical properties (e.g., equal interval units) well suited for analytic models of academic growth. The $\mathrm{W}$ scores for each subtest are centered on a value of 500, the approximate average performance of beginning fifth-grade students. The $\mathrm{W}$ scores for both subtests demonstrate moderate to high internal reliability. Cronbach's alphas ranged from .88 to .92 for letter-word identification and from . 80 to .83 for applied problems. Because scores for the applied problems and letter-word subtests were highly correlated, individual scores were averaged to create an overall index of children's achievement (see Hamre and Pianta 2005).

Maternal depression-At the 54th month and the first, third, and fifth grade data collections, mothers completed the "my feelings" questionnaire, an adaptation of the Center of Epidemiological Studies Depression (CES-D) Scale (Radloff 1997). Mothers were asked to circle one of four responses that best described how often they experienced certain feelings (e.g., felt sad, lonely, everything was an effort) during the past week $(0=$ rarely, $3=$ most of the time), and responses were summed to create a scale of depression ranging from 0 to 60 . This scale demonstrated high internal reliability (alphas ranged from .90 to .91). Because scores for maternal depression were highly skewed, we transformed these scores by taking the square root. The maximum value for this transformed score of depression was 7.75 .

Maternal education-During the one month interview, mothers reported the total number of years of education they had received and their highest level of degree attainment. Dummy variables were used to sort mothers into five education groups (less than high school, high 
school graduate, some college, college graduate, graduate work or degree). Unfortunately, we could not account for increases in maternal education since the child's birth because of documented problems with these reports (McKenna, Batten and Appelbaum 1995). Although some mothers reported additional schooling, few reported additional degree attainment.

Additional academic factors-To account for the onset of formal instruction and its contribution to learning trajectories, longitudinal models included first, third, and fifth grade measures of classroom quality derived from the "classroom observation system." The classroom observation system is a standardized procedure of classroom observation (see Pianta et al. 2007). Trained observers recorded characteristics of the teacher, child, and classroom during two 44-minute cycles. The total quality composite at all three time points represented the sum of three ratings of teacher behavior (e.g., sensitivity/responsivity) and four ratings of classroom organization and climate (e.g., classroom management) that vary across grades. Cronbach's alphas ranged from .76 at third grade to .89 at first and fifth grades. To account for the potential for children's cognitive and intellectual development to influence both maternal depression and children's own subsequent learning, models also controlled for a measure of school readiness. At 36 months, children took the Bracken Basic Concepts test, a set of individually administered subtests that assess cognitive ability (Bracken 1984). Scores for all subtests were summed to create a composite measure that ranged from 0 to 61 and displayed high internal reliability (alpha $=.93$ ).

Time-invariant covariates-To account for important sociodemographic factors that are associated with mental health and academic progress, we included covariates for the child's gender $(0=$ male, $1=$ female), mother's age at the focal child's birth (measured continuously), and mothers' race-ethnicity (dummy variables for white, black, and other). We considered using the squared term for age, following some past studies that emphasize the parabolic pattern of depression by age (Mirowsky and Ross 1992), but we retained the non-transformed version after subsidiary analyses revealed no difference between the two approaches. A final set of covariates included dummy variables for study site.

Time-varying covariates-Other important correlates of educational attainment, depression, and children's achievement that vary over time must also be taken into account. We include an income-to-needs ratio for each family at 54 months and at first, third, and fifth grades, which was calculated by dividing maternal reports of all sources of household income by the federal poverty threshold for that family size. Family structure at 54 months and at first, third, and fifth grades was captured by a binary marker $(1=$ two biological married parents, $0=$ other family structures). Last, maternal employment at each time point was based on mothers' reports of the average number of hours per week in a job. Mothers working 10 or more hours per week were assigned a value of 1 for employed (Meadows et al. 2007; McLoyd 1998; Muller 1995).

\section{Analytic Strategy}

The first analytical step was to estimate trajectories of maternal depression and child achievement with latent growth curve modeling. In this type of random coefficient 
modeling, we used time-specific measures of depression and achievement to estimate an underlying growth trajectory, a single line that best fits the multiple time-specific measures. This trajectory is characterized by latent factors- the intercept and slope-and allows us to estimate changes in a behavior over time, as well as individual differences in this change (Bollen and Curran 2005). We estimated unconditional models (e.g., with no predictors) for maternal depression from 54 months to fifth grade and for child achievement from first grade to fifth grade. Factor loadings for the depression slope were set to $-1,0,2$, and 4 to approximate intervals centered on first grade. For achievement, we set the first two slope factor loadings to 0 and 2 . Because the slope of achievement was not perfectly linear (there was a deceleration between times 2 and 3 that was 68 percent the rate of change between times 1 and 2), freeing the third factor loading was an efficient way to estimate this nonlinear slope factor.

Next, we regressed the intercept and slope factors for maternal depression and child achievement on maternal education, adjusting for the full set of control measures (except school readiness, which was added in the following step to account for potential spuriousness between trajectories of depression and achievement). Specifically, we entered (1) three time-varying covariates (income, employment, family structure) as predictors of the time-specific measures of depression, (2) four time-varying covariates (the same three plus classroom quality) as predictors of the time-specific measures of child achievement, and (3) the time-invariant covariates as predictors of the intercepts and slopes. We then combined the two models, with the child achievement intercept regressed on the intercept and slope of maternal depression, and the slope of child achievement regressed on the intercept and slope of depression. This model added school readiness as an additional predictor of all growth curve factors. We also estimated covariances among the child achievement intercept and maternal depression slope, the maternal depression intercept and maternal depression slope, and the child achievement intercept and child achievement slope.

These modeling steps provided the basic information needed to assess the dynamic longitudinal mediational pathway between maternal education and child achievement through maternal depression. In particular, the models allow us to determine whether maternal education and maternal depression predicted the outcome (achievement trajectories), and whether maternal education predicted the hypothesized mediator (maternal depression trajectories). The models also allow us to estimate whether taking into account the association between mediator and outcome attenuated the original association between maternal education and the outcome (MacKinnon, Fairchild, and Fritz 2007).

Next, we explored whether the link between maternal depression and child achievement varied as a function of maternal education. We hypothesized that maternal education would select women into depression trajectories in a way that would then influence children's academic achievement during school (mediation), but also that any level of depression would be more consequential for the achievement trajectories of children with less-educated mothers (moderation). To examine moderation, the same model just described was reestimated within maternal education groups. Initially, we used the five categories of maternal education, but, based on the results of this modeling pass (available from the authors upon 
request), we divided mothers into two education groups (low = "high school or less," high = "some college or more"). ${ }^{1}$

We estimated all models in Mplus (Muthén and Muthén 2004), which employs full information maximum likelihood (FIML) to account for missing data and correct for nonresponse and attrition (Allison 2001). Quality of models and overall fit were evaluated by the comparative fit index (CFI) and root mean-square error of approximation (RMSEA). The CFI ranges from 0 to 1 . Values over .90 generally indicate acceptable levels of model fit. Conventionally, we accept RMSEA values of less than .05 as indicators of good model fit.

\section{Results}

As a starting point, Table 1 presents descriptive statistics that provide a sense of the sociodemographic profiles of mothers in the sample with different levels of educational attainment. Table 1 reveals that, as maternal education increased, so did mothers' likelihood of being white, married to their children's fathers, more financially secure, and older at the time of the child's birth. On the other hand, mothers with less education were more likely to be single, African American, younger, and less financially secure. Additionally, as maternal educational attainment increased, so did children's school readiness and the quality of their school classrooms. Educational attainment did not differentiate mothers on labor force participation, except that mothers without a high school degree had lower employment rates.

Importantly, the statistics in Table 1 also reveal that greater levels of maternal education were associated with less depression among mothers. For example, the difference in depression between the highest and lowest education groups is nearly one standard deviation at 54 months, although these differences and their relative significance varied across grades. Greater levels of maternal education were also associated with higher levels of academic achievement during elementary school among children. Of course, maternal depression and child achievement are also dynamic processes rather than static attributes. To capture this dynamism, we turned to growth curve modeling, momentarily putting maternal education aside.

The unconditional growth curve model for maternal depression (not shown) revealed that the average mother had low levels of depression when her child was pre-school aged $(\mathrm{M}=2.48$ for intercept $)$ that increased slightly as her child moved through elementary school $(\mathrm{M}=.03$ for slope). The average child added 17 points per year to his or her average test score between first grade $(\mathrm{M}=461.44$ for intercept) and fifth grade ( $\mathrm{M}=17.24$ for slope). However, the significant variance estimates for all factors indicated that women and children in the sample varied substantially around these means $(1.28, p<.001$ for depression

\footnotetext{
${ }^{1}$ As noted in the methods section, we originally estimated our modeling procedure in a group modeling framework using the fivecategory maternal education demarcation. This initial step revealed that the intercept of maternal depression was significantly associated with the intercept and slope of child achievement for the mothers with less than a high school education and for mothers with a high school degree. Among the mothers with some college education, the coefficients followed a similar pattern but did not reach statistical significance. Based on these results and for the sake of parsimony, therefore, we created two maternal education groups for the final analyses, grouping mothers with some college experience with those mothers who had a college degree (or greater) and comparing them to a second group of women comprised of high school graduates and dropouts.
} 
intercept; .03, $p<.05$ for depression slope; 248.8, $p<.05$ for achievement intercept; and $5.17, p<.05$ for achievement slope). That variation is important because it might be attributable to maternal education.

\section{The Link between Maternal Depression and Children's Achievement}

The conditional models presented in Table 2 were attempts to identify possible sources of variation in the latent factors for the maternal depression and child achievement growth curves. In the process, they allowed us to test the first two criteria for mediation: Did maternal education predict the outcome (child achievement) and hypothesized mediator (maternal depression)?

In Table 2, model 1 regressed the intercept and slope of maternal depression on maternal education, the time-varying covariates (e.g., income), and the time-invariant covariates (e.g., race). Starting with the intercept, compared to mothers with a high school degree, mothers without a high school degree had significantly higher levels of depression when children were 54 months old $(b=.32, p<.05)$, those with some college education were marginally less depressed $(b=-.18, p<.10)$, and those with a college $(b=-.44, p<.001)$ or advanced degree $(b=-.56, p<.001)$ were significantly less depressed. This last difference exceeded two times the standard deviation of the depression intercept. Turning to the slope, college graduates had slight increases in depression as their children moved into elementary school and through fifth grade $(b=.05, p<.10$ for college degree; $b=.07, p<.05$ for advanced degree) relative to high school graduates (who were not significantly different from women in the remaining categories). This small increase in depression among college-educated mothers is more than likely a case of regression to mean, and it did little to even out the gap in depression between more and less-educated mothers. Thus, during the critical preschool years when children spend more time at home, more educated mothers demonstrated less depressive symptomology. These initial differences persisted, albeit in slightly reduced form as their children moved through elementary school.

Model 2 presents the results for child achievement. At the start of elementary school, children differed in expected ways by their mothers' level of educational attainment (significant coefficients for the achievement intercept for all maternal education categories). Indeed, the children of women with advanced degrees scored about 10 points higher than their peers with high school-educated mothers, a difference two times the size of the intercept standard deviation. These children, however, did not differ in their rates of achievement growth through fifth grade. Thus, the children of more educated mothers started off school with a clear academic advantage and then maintained this advantage in stable form over the next few years.

To examine the interplay between these trajectories, we combined the maternal depression and child achievement growth curves into one model and examined the relations among the intercepts and slopes of each growth curve. This model also added school readiness as a predictor of the child achievement and maternal depression latent factors to address the possibility that children's early cognitive capacities selected them into trajectories of maternal depression and later achievement in ways that might produce misleading estimates 
of the associations between the two. Table 3 presents the focal coefficients from this model (time-varying coefficients appear in the Appendix).

Results from these models indicated that neither the intercept nor the slope of maternal depression predicted the intercept or slope of child achievement. Indeed, the depression latent factors and the achievement latent factors did not covary with each other at all. Thus, even though less-educated mothers were more depressed than other mothers, maternal depression could not be a mediator of the already-established association between maternal education and child achievement trajectories because the children of depressed mothers did not have different achievement trajectories than their peers. For the full sample at least, we uncovered no evidence of the hypothesized mediational pathway.

One set of findings that did emerge from these models warrants discussion. Specifically, the child achievement intercept was significantly and inversely associated with the child achievement slope, and the school readiness measure significantly and negatively predicted the child achievement slope. These results indicated that children who began school with more developed academic skills had less steep upward learning curves once school began. Alternatively, children with less developed academic skills posted greater gains once formal instruction began, although these children did not ever fully catch up with their more schoolready peers. This pattern has been reported in studies using both the SECCYD and other data sets (Downey, von Hippel, and Broh 2004; NICHD Early Child Care Research Network 2005).

\section{Maternal Education as a Moderator}

Although maternal depression did not mediate the longitudinal association between maternal education and child achievement in the full SECCYD sample, the three focal links could have been related in another way, namely, in a moderational pathway in which the association between maternal depression and child achievement varied as a function of maternal education. In other words, would children of more highly educated mothers be less affected academically by the same level of maternal depression than children of lesseducated mothers? We investigated this possibility by re-estimating the model just described within each maternal education group. Based on these results (see note 1), we divided the sample into two maternal education groups. The low education group included high school graduates and dropouts. The high education group included women with at least some college experience. We estimated the models simultaneously in a group modeling framework, and we present the results of this group modeling step in Table 4.

In the low maternal education group, maternal depression was significantly associated with both the intercept and slope of child achievement. With increases in maternal depression, children's early achievement levels were lower $(b=-2.96, p<.01)$, but their over-time achievement gains were slightly greater $(b=.71, p<.05)$. Again, the magnitude of the positive increase on the slope factor was not big enough to offset the initial gap on the intercept. Thus, the children of less-educated, more depressed mothers started off school with less-developed academic skills than their peers with more educated, less depressed mothers. However, those children of less educated, more depressed mothers made up a small fraction of the difference as they moved through school. Turning to the high maternal 
education group, the maternal depression and child achievement latent factors were not related to each other, as was the case for the full sample.

To investigate this finding more closely, we attempted to identify critical timing points. Would the associations between maternal depression and child achievement observed in the low maternal education group be specific to any one time point, or were they consistent as children moved through school? To answer this question, we turned from a latent growth curve approach to a cross-lagged autoregressive modeling strategy. In this model, maternal depression at each time point was used to predict maternal depression and child achievement at the following time point while child achievement at each time point was used to predict maternal depression and child achievement at the following time point (Bollen and Curran 2005). We estimated this model within maternal education groups using group modeling, and we employed a reduced set of covariates (income, mother's age at birth, and raceethnicity) that were selected based on results from previous models and optimal model fit.

The results from this model (available upon request) reveal that, for the low maternal education group, higher levels of maternal depression measured when children were 54 months old were associated with lower levels of academic achievement when children were in first grade $(b=-1.77, \mathrm{SE}=.81)$. Maternal depression and child achievement were not significantly associated with each other in either direction at any other time point for either the low or high education group. This pattern suggests that maternal depression was only a problem, academically speaking at least, as the children of less-educated mothers transitioned into school.

In sum, maternal education was associated with maternal depression, but maternal depression was only associated with child achievement for mothers with lower educational attainment. Putting these two sets of findings together, less-educated mothers were more likely than other mothers to be depressed when their children were approaching the start of formal schooling, and their children were the one subset in a critical period of early childhood for whom maternal depression posed an academic risk.

\section{Sensitivity Analyses}

To bolster confidence in these conclusions, we considered whether there may have been an insufficient number of highly educated mothers in our sample with multiple depressive symptoms to detect an effect of maternal depression on children's achievement. Such sparse cell sizes could be particularly problematic if the effect of maternal depression on children's achievement were concentrated among the most severely depressed mothers. To test for this possibility, we first divided the continuous measure of maternal depression at 54 months into quintiles, created a set of five dummy variables to measure location in each of the five, and then regressed children's first grade achievement on this set (the lowest quintile was the omitted reference category) within each maternal education group, controlling for timeinvariant and time-varying covariates measured at first grade. These results (not shown) reveal a significant association between the highest depression quintile $(b=-9.24, \mathrm{SE}=$ 3.66) and children's first grade achievement for the low education group. None of the coefficients for the other quintile dummies were significant. Echoing the earlier findings, maternal depression quintiles and child achievement were not significantly associated for the 
high education group. Thus, the negative effects of maternal depression on children's achievement for the low education group only emerged when mothers were severely depressed.

Given this finding, it was necessary to examine whether the nonsignificant association between severe depression (quintile 5) and child achievement for the high education group was a consequence of few of these mothers having severe depression. Cross-tabulated frequency distributions (not shown) reveal that within the high education group 16 percent had severe depression ( $f=112$ ), compared to 27 percent among the low education group ( $f=$ 71). Therefore, although a smaller proportion of the high education group had severe depression than the low education group, it appears that there are enough severely depressed women in the high education group to detect an effect of severe depression on children's first grade achievement. To verify this, we conducted a post hoc power analysis using $\mathrm{G}^{*}$ Power, a general power analysis program (Faul et al. 2007). Specifying alpha levels at .05, these results indicate that there is sufficient power in this sample to detect even small effect sizes of depression quintiles on child achievement $(f=.15$, power $=.91 ; f=.20$, power $=1.00)$.

\section{Discussion and Conclusion}

The intergenerational transmission of inequality has been repeatedly demonstrated to result from the human and financial returns to education that parents use to promote their children's schooling and long-term status attainment (Sirin 2005). Yet parent education also is associated with well-documented health advantages that may affect children's learning and the status-attainment process (Mirowsky and Ross 2003). Specifically, reduced maternal mental health, and maternal depression in particular, can negatively affect the parenting practices identified in prior research as most important to children's learning (McLoyd 1998). Whether these maternal mental health advantages form a link between maternal educational attainment and academic advantages among children is a question that has not been adequately examined.

In order to answer this question, this study applied a dynamic approach using latent growth curve modeling to explore the link between trajectories of maternal depression and trajectories of achievement in connection with women's educational attainment. We expected that the psychological resources that education imparts would result in lower levels and smaller increases in depression among more highly educated mothers, and greater achievement gains among their children. We also expected that the other personal resources that education cultivates would serve to buffer children of well-educated mothers from the academic risks that maternal depression may present.

Our findings provide partial support for these two expectations. First, both maternal depression and children's achievement did follow clear and expected patterns across levels of maternal education, although maternal depression did not explain the positive association between maternal educational attainment and children's achievement. At the same time, we did find evidence that the link between maternal depression and children's achievement was conditioned by maternal education. These findings suggest that, although maternal depression may not be an explanation for why children of more educated parents tend to 
perform better in school, something more subtle is at work. Specifically, only the learning of children whose mothers had high school degrees or less was vulnerable to their mothers' depression. That these children's mothers experienced the greatest depressive symptoms suggests a "double disadvantage" of growing up with a mother with less education. Such a double disadvantage could be an important means by which inequality is reproduced.

We should emphasize, however, that the negative association between maternal depression and the learning of children with less-educated mothers was limited to a specific developmental window among the most severely depressed mothers. Mothers' severe depression immediately before the transition to school was negatively associated with children's learning at the onset of school. Once teachers, peers, and schools became more proximal to children's learning, however, severe maternal depression no longer posed a risk. These findings cast light on the initial stages of inequality, which, according to the school transition model, begins when children acquire important academic, cognitive, and psychosocial skills that prepare them to get an early jump on learning once they begin school (Entwisle and Alexander 1993). Indeed, as our findings indicate, children who started school with more academic skills maintained a stable academic advantage throughout elementary school over children who began school with fewer academic skills. These findings also suggest that, although moderate depression may not be all too consequential to children's learning, severe depression can have a considerable effect.

Given these findings, why might maternal depression be less relevant to the children of more educated mothers immediately before the transition to elementary school? Certainly, economic and familial factors associated with maternal educational attainment grants mothers access to resources that can help buffer children from the effects of their mothers' depression (e.g., social networks, therapy, or medication) and bolster their learning (e.g., home learning materials, family structure stability). We should point out, however, that our findings indicate that, at least for income and family structure, these resources seemed more important to children's learning once children had begun school (see Appendix). Thus, in addition to the material and social resources associated with education, persistence in the educational system engenders skills (e.g., organizational), knowledge (about children's developmental needs), and values (about schooling) that may lead more educated women to manage their children's time (e.g., enriching child care, home learning games, lessons) in ways that both minimize the potential risks of their depression to their children and maximize their children's academic development (Augustine et al. 2009; Lareau 2004; Magnuson 2007; Oyserman et al. 2002; Sayer et al. 2004). Children whose mothers did not continue their education past high school, on the other hand, may lack many of these learning opportunities and activities and be more influenced by the immediate impact of depression on their mothers' parenting.

Although we have taken steps to reduce the likelihood that other factors are driving the observed links among mothers' education, depression, and their children's achievement, we must acknowledge that we could not account for potential unobserved confounding factors. Aside from taking a dynamic approach and controlling for key covariates, we have also controlled for children's early cognitive skills, which addresses the possibility that women with more education possess certain cognitive traits that are passed on to their children. 
Moreover, our modeling strategy allowed us to test and reject the idea that children's academic difficulties may bring about, in part, mothers' depressive symptoms.

Importantly, we have not teased out the role of race-ethnicity in these linkages among maternal education, depression, and children's achievement, but race-ethnicity seems to be a complicating factor. For example, in the full sample, African American mothers had more depression, and their children made smaller academic gains throughout elementary school. The group modeling step of the analysis shows, however, that these patterns were largely concentrated in the high maternal education group. Unfortunately, although the original sample mirrored the racial-ethnic composition of the general population, the African American sub-population is skewed toward being more disadvantaged and less educated. Thus, this question would be better addressed with a larger sample containing a more socioeconomically diverse subsample of African Americans.

The goal of this study was to understand the importance of mothers' mental health for the intergenerational transmission of advantage. The results of this study cast new light on the role of maternal depression in the link between mothers' educational attainment and their children's learning trajectories. Not only do mothers with less education experience more depressive symptoms and more severe depression, their children also are affected by such depression. As a consequence, this double disadvantage sets these children on different academic paths than their more advantaged peers. These findings highlight an important mechanism in the reproduction of social inequality and the salience of health-related factors in this process.

\section{Acknowledgments}

The authors would like to thank John Mirowsky for his helpful comments on the analysis.

Funding: The authors acknowledge the support of National Institute of Child Health and Human Development grants R24 HD42849 (PI: Mark Hayward), U10 HD025460 (PI: Robert Bradley and Co-PI: Robert Crosnoe), and R01 HD055359 (PI: Robert Crosnoe) to the Population Research Center, University of Texas at Austin. Opinions reflect those of the authors and not necessarily those of the granting agencies.

\section{Appendix}

\section{Parameter Estimates for Time-Varying Covariates from Combined Latent Growth Curve Models of Maternal Depression and Child Achievement $(N=1,012)$}

\begin{tabular}{|c|c|c|c|c|c|c|c|}
\hline & \multicolumn{7}{|c|}{$B(S E)$} \\
\hline & \multicolumn{4}{|c|}{ Maternal Depression Indicators } & \multicolumn{3}{|c|}{ Child Achievement Indicators } \\
\hline & 54 Months & First Grade & Third Grade & Fifth Grade & First Grade & Third Grade & Fifth Grade \\
\hline $\begin{array}{l}\text { Family } \\
\text { income } 54 \\
\text { months }\end{array}$ & $-.01(.01)$ & - & - & - & & - & - \\
\hline $\begin{array}{l}\text { Maternal } \\
\text { employment } \\
54 \text { months }{ }^{a}\end{array}$ & $-.25(.10)$ & - & - & - & & - & - \\
\hline
\end{tabular}

J Health Soc Behav. Author manuscript; available in PMC 2017 August 15. 


\begin{tabular}{|c|c|c|c|c|c|c|c|}
\hline & \multicolumn{7}{|c|}{$B(S E)$} \\
\hline & \multicolumn{4}{|c|}{ Maternal Depression Indicators } & \multicolumn{3}{|c|}{ Child Achievement Indicators } \\
\hline & 54 Months & First Grade & Third Grade & Fifth Grade & First Grade & Third Grade & Fifth Grade \\
\hline $\begin{array}{l}\text { Family } \\
\text { structure } 54 \\
\text { months } b\end{array}$ & $-.25^{*}(.10)$ & - & - & - & & - & - \\
\hline $\begin{array}{l}\text { Family } \\
\text { income first } \\
\text { grade }\end{array}$ & - & $-.03 *(.02)$ & - & - & $.36 *(.16)$ & - & - \\
\hline $\begin{array}{l}\text { Maternal } \\
\text { employment } \\
\text { first grade }\end{array}$ & - & $-.13{ }^{\dagger}(.07)$ & - & - & $.87(.79)$ & - & - \\
\hline $\begin{array}{l}\text { Family } \\
\text { Structure } \\
\text { first grade }\end{array}$ & - & $-.35^{* * *}(.10)$ & - & - & $.58(1.01)$ & - & - \\
\hline $\begin{array}{l}\text { Classroom } \\
\text { quality first } \\
\text { grade }\end{array}$ & - & - & - & - & $.07(.06)$ & - & - \\
\hline $\begin{array}{l}\text { Family } \\
\text { income } \\
\text { third grade }\end{array}$ & - & - & $-.05^{* * *}(.01)$ & - & - & $.03(.09)$ & - \\
\hline $\begin{array}{l}\text { Maternal } \\
\text { employment } \\
\text { third grade }\end{array}$ & - & - & $.07(.07)$ & - & - & $.33(.51)$ & - \\
\hline $\begin{array}{l}\text { Family } \\
\text { structure } \\
\text { third grade }\end{array}$ & - & - & $-.24^{* *}(.09)$ & - & - & $-.47(.69)$ & - \\
\hline $\begin{array}{l}\text { Classroom } \\
\text { quality third } \\
\text { grade }\end{array}$ & - & - & - & - & - & $.10(.07)$ & - \\
\hline $\begin{array}{l}\text { Family } \\
\text { income fifth } \\
\text { grade }\end{array}$ & - & - & - & $-.04(.01)$ & - & - & $.12(.08)$ \\
\hline $\begin{array}{l}\text { Maternal } \\
\text { employment } \\
\text { fifth grade }\end{array}$ & - & - & - & $.01(.09)$ & - & - & $.15(.52)$ \\
\hline $\begin{array}{l}\text { Family } \\
\text { structure } \\
\text { fifth grade }\end{array}$ & - & - & - & $-.24^{*}(.10)$ & - & - & $-.30(.65)$ \\
\hline $\begin{array}{l}\text { Classroom } \\
\text { quality fifth } \\
\text { grade }\end{array}$ & - & - & - & - & - & - & $.11(.08)$ \\
\hline $\begin{array}{l}p^{t} p<.10 ; \\
* p<.05 ; \\
* * x<.01 ; \\
* * * 0.001\end{array}$ & & & & & & & \\
\hline
\end{tabular}

\section{References}

Alexander, Karl, Entwisle, Doris. Achievement in the First Two Years of School: Patterns and Processes. Chicago, IL: The University of Chicago Press; 1988.

Alexander, Karl, Entwisle, Doris, Bedinger, Samuel. When Expectations Work: Race and Socioeconomic Differences in School Performance. Social Psychology Quarterly. 1994; 57:283-99.

J Health Soc Behav. Author manuscript; available in PMC 2017 August 15. 
Alexander, Karl L., Entwisle, Doris R., Olson, Linda S. Lasting Consequences of the Summer Learning Gap. American Sociological Review. 2007; 72:167-80.

Allison, Paul. Missing Data. Thousand Oaks, CA: Sage Publications; 2001.

Amato, Paul R., Fowler, Frieda. Parenting Practices, Child Adjustment, and Family Diversity. Journal of Marriage and Family. 2002; 64:703-16.

Augustine, Jennifer March, Cavanagh, Shannon, Crosnoe, Robert. Maternal Education, Early Child Care, and the Reproduction of Advantage. Social Forces. 2009; 88:1-30.

Bianchi, Suzanne, Robinson, John. What Did You Do Today? Children's Use of Time, Family Composition, and the Acquisition of Social Capital. Journal of Marriage and the Family. 1997; 59:332-44.

Bollen, Kenneth A., Curran, Patrick J. Latent Curve Models: A Structural Equation Approach. New York: Wiley; 2005.

Bornstein, Marc, Bradley, Robert. Socioeconomic Status, Parenting, and Child Development. Mahwah, NJ: Lawrence Erlbaum; 2003.

Bracken, Bruce A. Bracken Basic Concept Scales. San Antonio, TX: Psychological Corporation; 1984.

Buchman, Claudia, DiPrete, Thomas A. The Growing Female Advantage in College Completion: The Role of Family Background and Academic Achievement. American Sociological Review. 2006; 21:515-41.

Carbonaro, William. A Little Help from My Friends' Parents: Intergenerational Closure and Educational Outcomes. Sociology of Education. 1998; 4:295-313.

Cavanagh, Shannon E., Huston, Aletha C. Family Instability and Child Well-Being. Social Forces. 2006; 85:551-81.

Chin, Tiffani, Phillips, Meredith. Social Reproduction and Childrearing Practices: Social Class, Children's Agency, and the Summer Activity Gap. Sociology of Education. 2004; 77:185-210.

Coleman, James. Social Capital and the Creation of Human Capital. American Journal of Sociology. 1988; 94:95-120.

Crosnoe, Robert L., Huston, Aletha C. Socio-economic Status, Schooling, and Developmental Trajectories. Developmental Psychology. 2007; 43:1097-1110. [PubMed: 17723038]

Currie, Janet, Moretti, Enrico. Mother's Education and the Intergenerational Transmission of Human Capital: Evidence from College Openings. The Quarterly Journal of Economics. 2003; 118:14951532.

Davis-Kean, Pamela. The Influence of Parent Education and Family Income on Child Achievement: The Indirect Role of Parent Expectations and the Home Environment. Journal of Family Psychology. 2005; 19:294-304. [PubMed: 15982107]

Downey, Douglas B., von Hippel, Paul T., Broh, Beckett A. Are Schools the Great Equalizer? Cognitive Inequality during the Summer Months and the School Year. American Sociological Review. 2004; 69:613-35.

Downey, Geraldine, Coyne, James C. Children of Depressed Parents: An Integrative Review. Psychological Bulletin. 1990; 108:50-76. [PubMed: 2200073]

Elder, Glen H. The Life Course as Developmental Theory. Child Development. 1998; 69:1-12. [PubMed: 9499552]

Entwisle, Doris, Alexander, Karl L. Entry into School: The Beginning School Transition and Educational Stratification in the United States. Annual Review of Sociology. 1993; 19:401-23.

Entwisle, Doris R., Alexander, Karl L., Olson, Linda S. Children, Schools, and Inequality. Boulder, CO: Westview; 1997.

Faul, Franz, Erdfelder, Edgar, Lang, Albert-Georg, Buchner, Axel. G*Power 3: A Flexible Statistical Power Analysis Program for the Social, Behavioral, and Biomedical Sciences. Behavior Research Methods. 2007; 39:175-91. [PubMed: 17695343]

Gennetian, Lisa, Magnuson, Katherine, Morris, Pamela. From Statistical Associations to Causation: What Developmentalists Can Learn from Instrumental Variables Techniques Coupled with Experimental Data. Developmental Psychology. 2008; 44:381-94. [PubMed: 18331130] 
George, Linda K., Lynch, Scott M. Race Differences in Depressive Symptoms: A Dynamic Perspective on Stress Exposure and Vulnerability. Journal of Health and Social Behavior. 2003; 44:353-69. [PubMed: 14582313]

Hamre, Bridget, Pianta, Robert C. Can Instructional and Emotional Support in the First-Grade Classroom Make a Difference for Children at Risk of School Failure? Child Development. 2005; 76:949-67. [PubMed: 16149994]

Hoover-Dempsey, Kathleen, Sandler, Howard M. Why Do Parents Become Involved in Their Children's Education. Review of Educational Research. 1997; 67:3-42.

Katz, Jennifer, Beach, Steven RH. Self-Verification and Depressive Symptoms in Marriage and Courtship: A Multiple Pathway Model. Journal of Marriage and the Family. 1997; 59:903-14.

Kingston, Paul W., Hubbard, Ryan, Lapp, Brent, Schroeder, Paul, Wilson, Julia. Why Education Matters. Sociology of Education. 2003; 76:53-70.

Lareau, Annette. Unequal Childhoods: Class, Race, and Family Life. Berkeley: University of California Press; 2004.

Lynch, Scott. Cohort and Life Course Patterns in the Relationship between Education and Health: A Hierarchical Perspective. Demography. 2003; 40:309-32. [PubMed: 12846134]

Mac Kinnon, David P., Fairchild, Amanda J., Fritz, Matthew S. Mediation Analysis. Annual Review of Psychology. 2007; 58:593-614.

Magnuson, Katherine. Maternal Education and Children's Academic Achievement During Middle Childhood. Developmental Psychology. 2007; 43:1497-1512. [PubMed: 18020827]

Mare, Robert, Maralani, Vida. The Intergenerational Effects of Changes in Women's Educational Attainments. American Sociological Review. 2006; 71:542-64.

McKenna, Patti, Batten, De Ann, Appelbaum, Mark. Technical Note 13: Inconsistencies in Maternal Education Data. 1995. Retrieved from Study of Early Child Care and Youth Development website: https://secc.rti.org

McLoyd, Vonnie. Socioeconomic Disadvantage and Child Development. American Psychologist. 1998; 53:185-204. [PubMed: 9491747]

Meadows, Sarah O., McLanahan, Sara S., Brooks-Gunn, Jeanne. Parental Depression and Anxiety and Early Childhood Behavior Problems across Family Types. Journal of Marriage and Family. 2007; 69:1162-77.

Mirowsky, John, Ross, Catherine E. Age and Depression. Journal of Health and Social Behavior. 1992; 33:187-205. [PubMed: 1401846]

Mirowsky, John, Ross, Catherine E. Education, Social Status, and Health. New York: Aldine de Gruyter; 2003.

Mistry, Rashmita, Biesanz, Jeremy, Taylor, Lorraine, Burchinal, Margaret, Cox, Martha J. Family Income and its Relation to Pre-School Children's Adjustment for Families in the NICHD Study of Early Child Care. Developmental Psychology. 2004; 40:727-45. [PubMed: 15355162]

Muller, Chandra. Maternal Employment, Parent Involvement, and Mathematics Achievement among Adolescents. Journal of Marriage and the Family. 1995; 57:85-100.

Muthén, Linda K., Muthén, Bengt O. Mplus User's Guide. Los Angeles, CA: Authors; 2004.

National Institute of Child Health and Human Development Early Child Care Research Network. Early Child Care and Children's Development Prior to School Entry: Results from the NICHD Study of Early Child Care. American Educational Research Journal. 2002; 39:133-64.

National Institute of Child Health and Human Development Early Child Care Research Network. Child Care and Child Development: Results from the NICHD's Study of Early Child Care and Youth Development. New York: Guilford Press; 2005.

Oreopoulos, Philip, Page, Marianne E., Stevens, Ann Huff. The Intergenerational Effects of Compulsory Schooling. Journal of Labor Economics. 2006; 24:729-60.

Oyserman, Daphna, Bybee, Deborah, Mowbray, Carol, MacFarlane, Peter. Positive Parenting among African American Mothers with a Serious Mental Illness. Journal of Marriage and Family. 2002; 64:65-77.

Palloni, Alberto. Reproducing Inequalities: Luck, Wallets, and the Enduring Effects of Childhood Health. Demography. 2008; 43:587-615. 
Pianta, Robert C., Cox, Martha J., Snow, Kyle L. School Readiness and the Transition to Kindergarten in the Era of Accountability. Baltimore, MD: Brookes Publishing Company; 2007.

Pianta, Robert C., Belsky, Jay, Houts, Renate, Morrison, Fred J. the National Institute of Child Health and Human Development Early Child Care Research Network. Opportunities to Learn in America's Elementary Classrooms. Science. 2007; 315:1795-96. [PubMed: 17395814]

Radloff, Lenore Sawyer. The CES-D Scale: A Self Report Depression Scale for Research in the General Population. Applied Psychological Measurement. 1997; 1:385-401.

Sayer, Liana C. Gender, Time, and Inequality: Trends in Women's and Men's Paid Work, Unpaid Work, and Free Time. Social Forces. 2005; 84:285-303.

Sayer, Liana C., Gauthier, Anne H., Furstenberg, Frank F. Educational Differences in Parents' Time with Children: Cross-National Variations. Journal of Marriage and Family. 2004; 66:1149-66.

Sirin, Selcuk R. Socioeconomic Status and Academic Achievement: A Meta-Analytic Review of Research. Review of Educational Research. 2005; 75:417-53.

Woodcock, Richard W., McGrew, Kevin, Mather, Nancy. Woodcock-Johnson III Tests of Achievement. Itasca, IL: Riverside Publishing; 2001.

\section{Biographies}

Jennifer March Augustine is a doctoral candidate in the Department of Sociology at the University of Texas at Austin and research trainee at the Population Research Center. Her research focuses on the intergenerational transmission of social status and the processes that link mothers' and children's educational pathways. Her current research integrates quantitative and qualitative methods to better understand how educational histories shape mothers' parenting philosophies and behaviors and, through these intergenerational relationships, children's early achievement.

Robert Crosnoe is Associate Professor of Sociology and a faculty associate in the Population Research Center at the University of Texas at Austin. His main field of interest is the life course and human development, with a special emphasis on social-psychological approaches to educational and health issues and how they can illuminate demographic inequalities. His current work focuses on the role of general developmental processes, including health and social relationships, in the educational experiences of young people, especially immigrant youth and poor youth. 


\section{을 \\ 골}

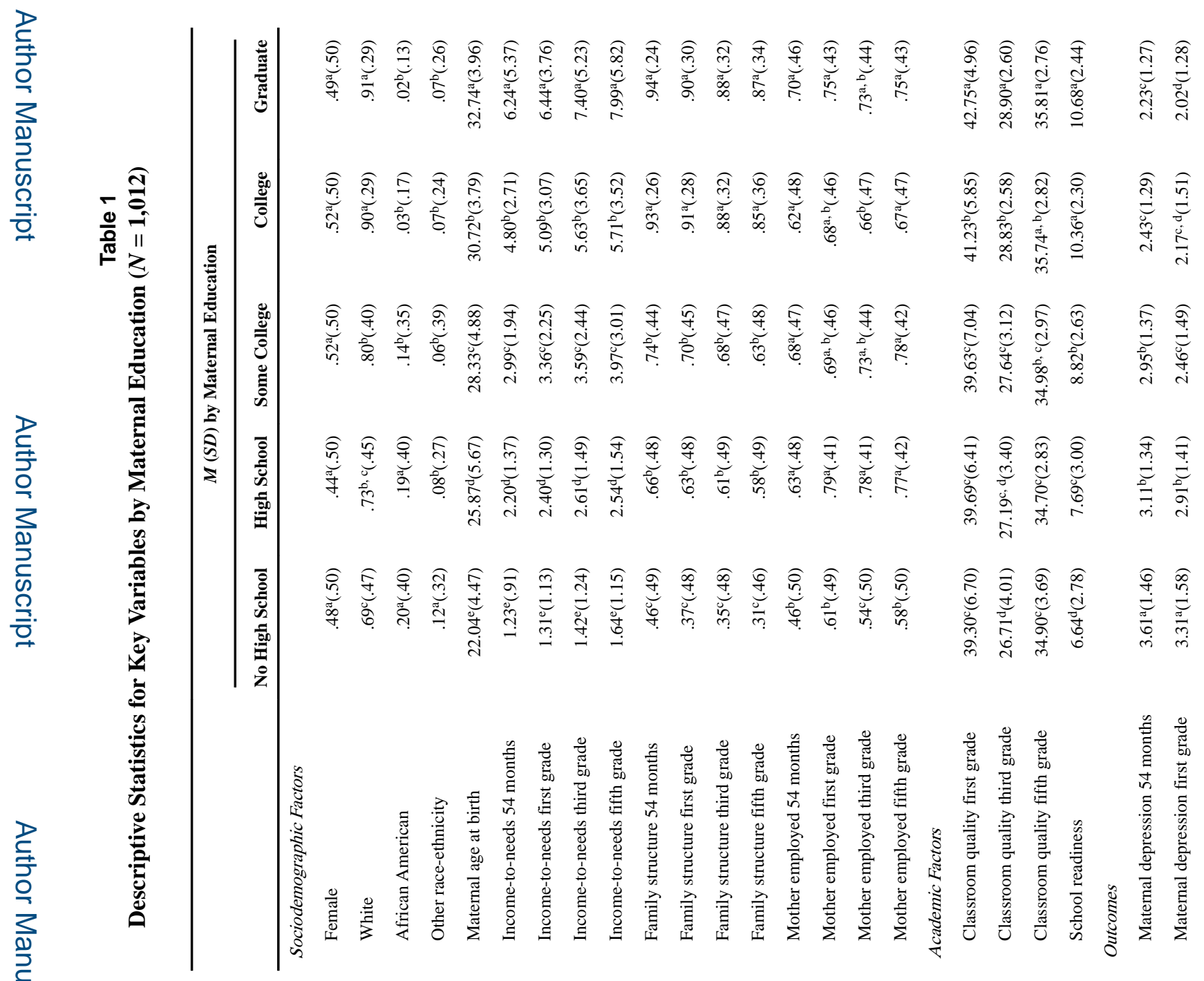

J Health Soc Behav. Author manuscript; available in PMC 2017 August 15. 


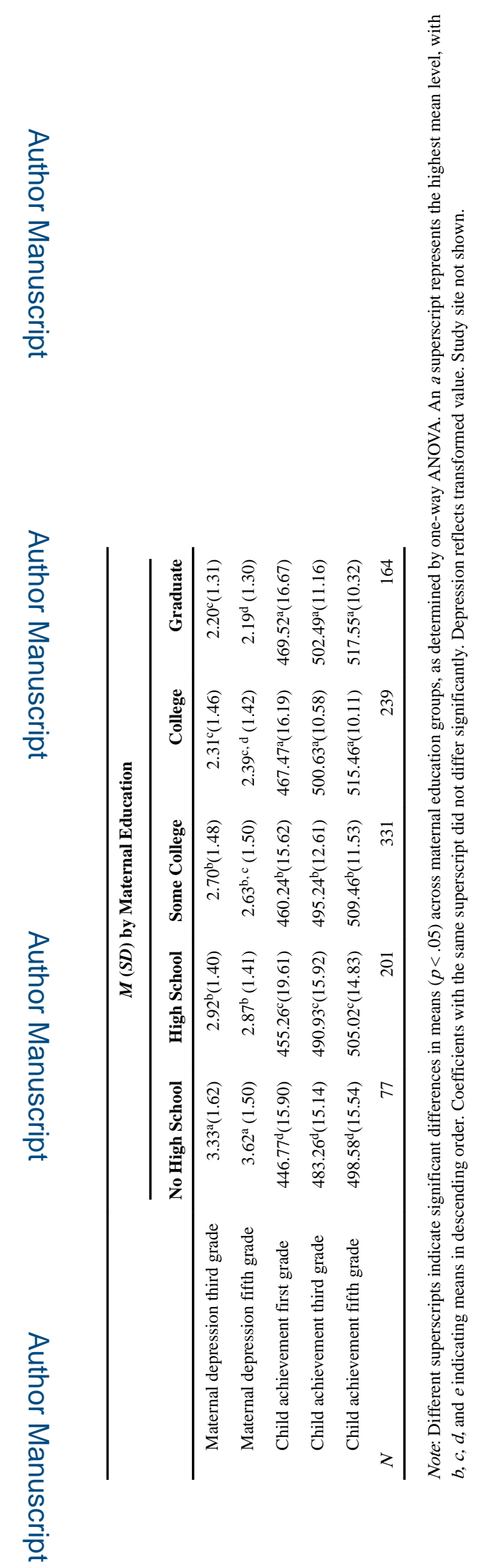


Table 2

Parameter Estimates for Growth Curve Models of Maternal Depression and Child Achievement $(N=1,012)$

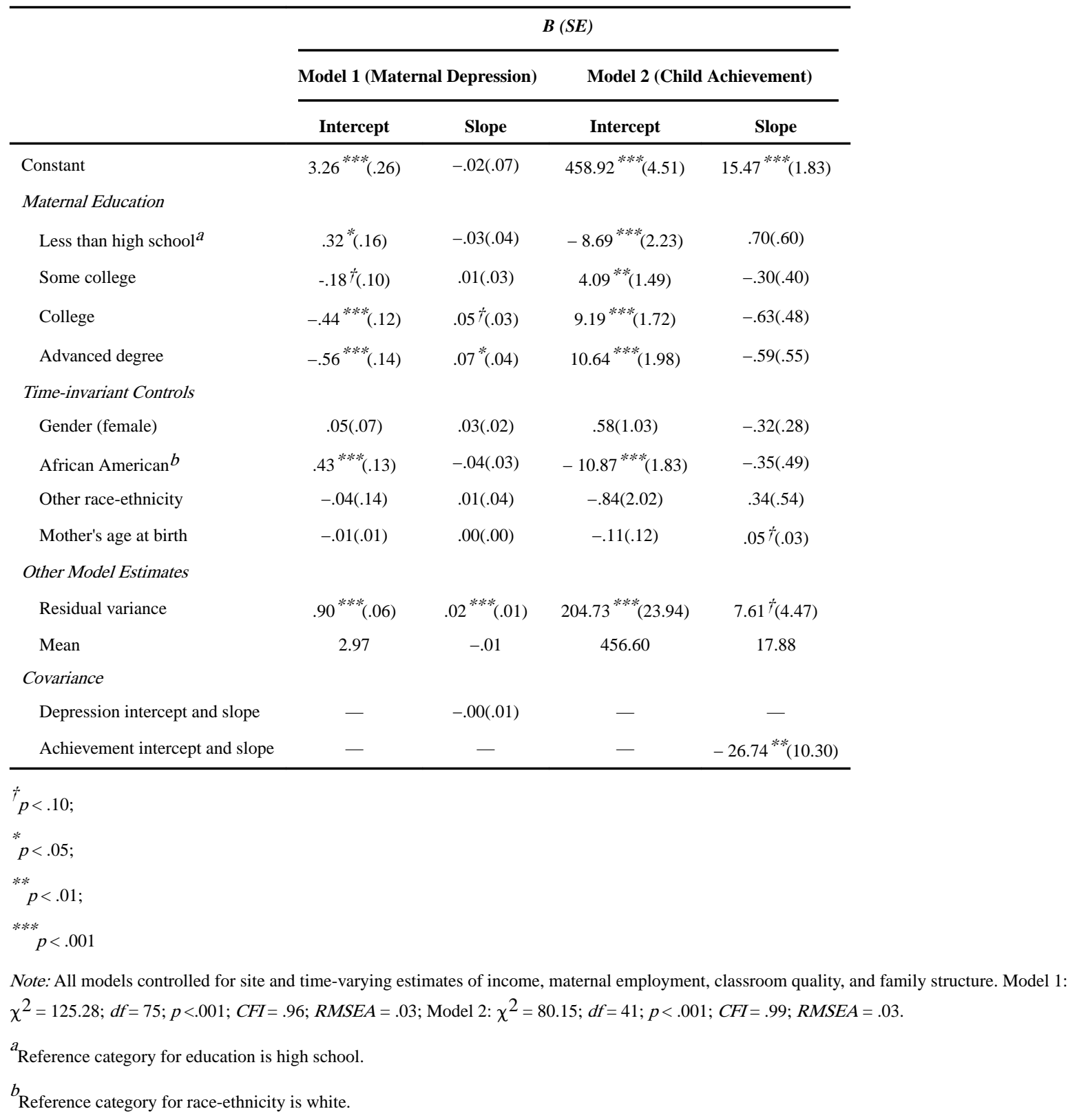


Table 3

Parameter Estimates for Combined Latent Growth Curve Models of Maternal Depression and Child Achievement $(N=\mathbf{1 , 0 1 2})$

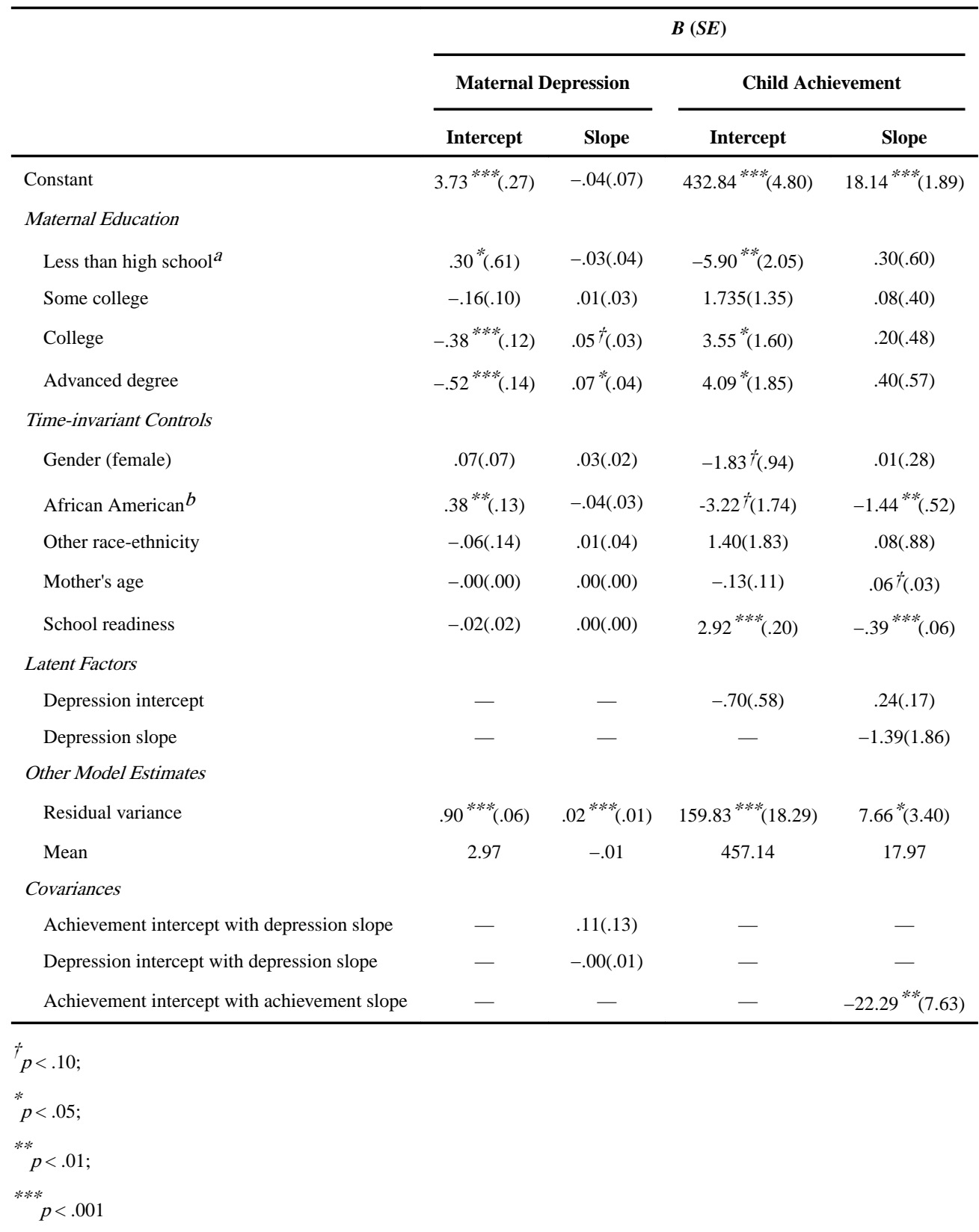

Note: All models controlled for site and time-varying measures of income, maternal employment, family structure, and classroom quality. See appendix for model 2 time-invariant parameter estimates. $\chi^{2}=230.06 ; d f=148 ; p<.001 ; C F I=.98 ; R M S E A=.02$.

${ }^{a}$ Reference category for education is high school.

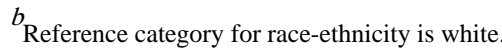




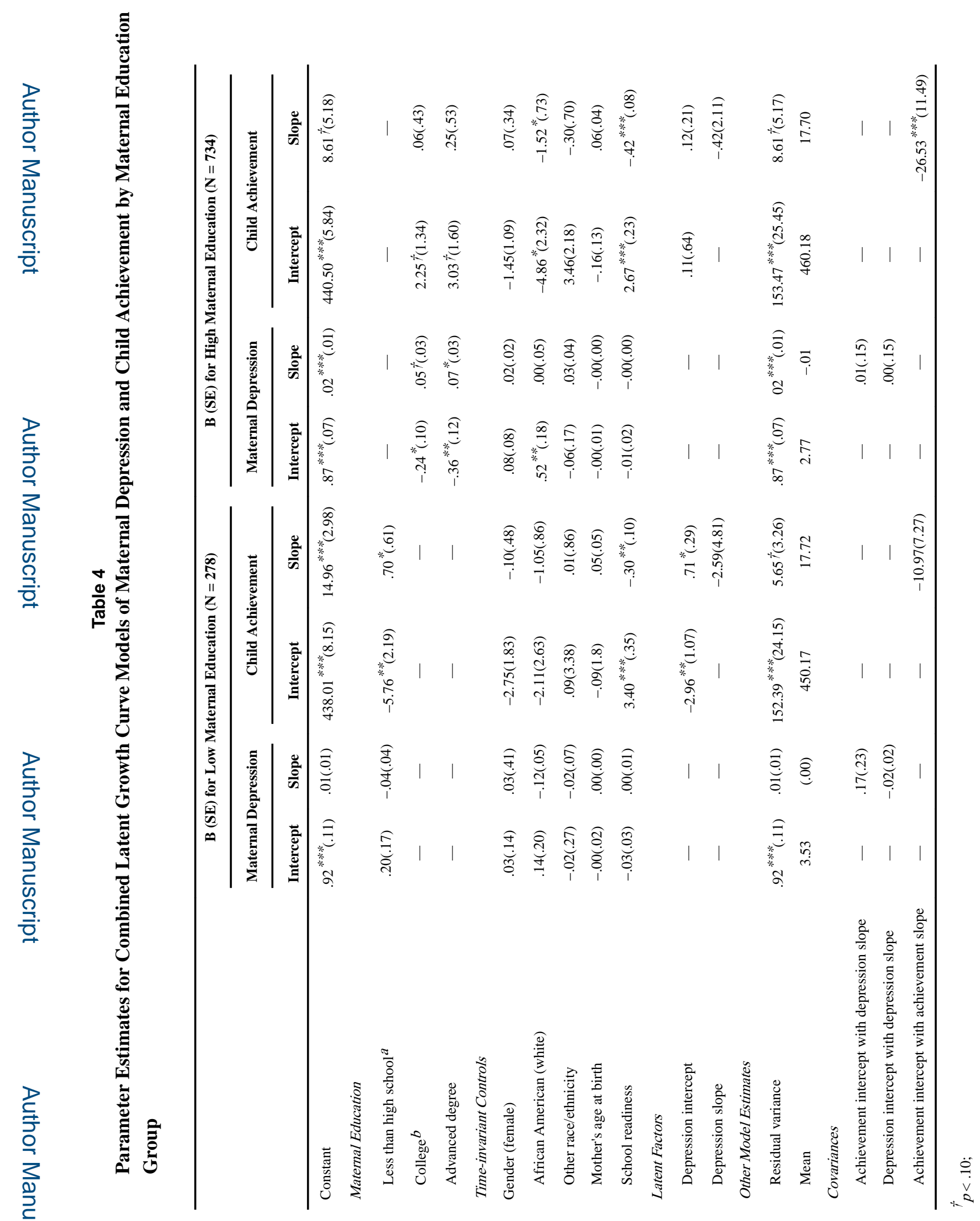




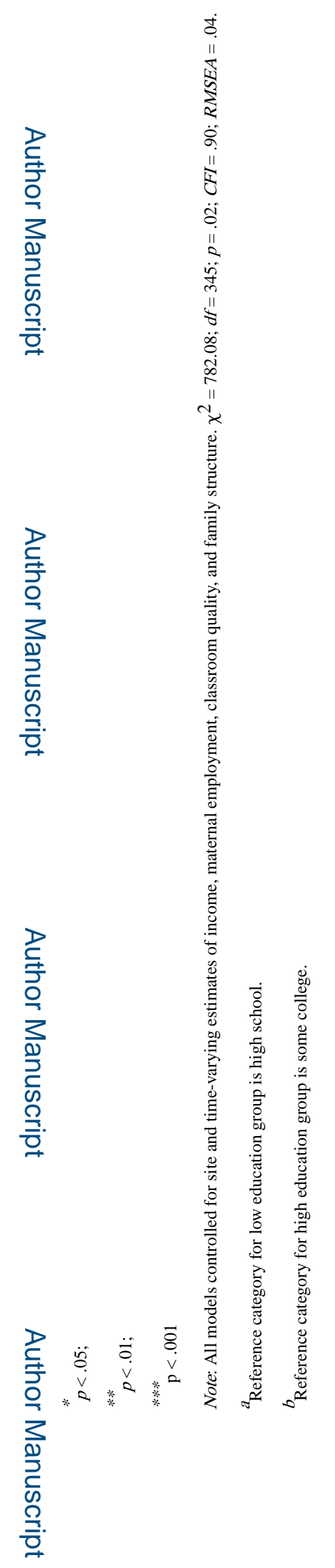

